\title{
Perfil florístico e estrutural do componente lenhoso em seis áreas de cerradão ao longo do bioma Cerrado
}

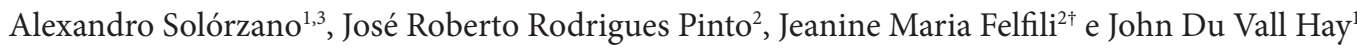

Recebido em 13/06/2011. Aceito em 14/02/2012

\begin{abstract}
RESUMO
(Perfil florístico e estrutural do componente lenhoso em seis áreas de cerradão ao longo do bioma Cerrado). Inúmeros trabalhos descrevem tanto o aspecto fisionômico e florístico do cerradão, no entanto, não há padronização do critério de inclusão, esforço amostral e tamanho das unidades amostrais o que dificulta as comparações e emergência de perfil estrutural para a vegetação lenhosa desta fitofisionomia. Buscamos com este trabalho descrever o perfil florístico-estrutural do componente lenhoso do cerradão, bem como avaliar o grau de sobreposição de espécies florestais, savânicas e generalistas. O trabalho foi realizado em seis áreas distribuídas nos estados de: MG, MS, MT, TO, PI e DF. A vegetação lenhosa do cerradão não apresentou estrutura homogênea ou consistência florística, apresentando-se como fisionomia bastante heterogênea. Estruturalmente a vegetação lenhosa apresentou grandes variações, com formações mais abertas e mais densas (densidade variando de 652 a 1.732 ind. ha $^{-1} \mathrm{e}$ área basal variando de 12,83 a $22,45 \mathrm{~m}^{2} \mathrm{ha}^{-1}$ ). A riqueza de espécies nas áreas vaiou de 49 (MS) a 124 (MT). Das 308 espécies registradas nas seis áreas apenas seis ocorreram em todas elas e 184 espécies foram exclusivas de uma das áreas. Florísticamente houve grande variação na composição de espécies e marcada dissimilaridade entre as áreas. Apesar de haver uma mistura de elementos florísticos savânicos e florestais, detectamos maior domínio de espécies savânicas com exceção da área MT que apresentou maior proporção de espécies florestais. O padrão geral de dissimilaridade florística e estrutural nas seis áreas indicaram grande heterogeneidade da distribuição da flora lenhosa do cerradão, seguindo o padrão de outras fitofisionomias do bioma Cerrado.
\end{abstract}

Palavras-chave: Cerrado, heterogeneidade, fitossociologia, espécies savânicas, espécies florestais

\begin{abstract}
(Structural and floristic profile of the woody component of six cerradão areas). A large number of studies describes the structure and composition of cerradão, however there is no standardization regarding data collection, rendering it difficult to conduct ample comparisons and the emergence of a structural and floristic profile for the cerradão. Our aim is to establish a structural-floristic profile of the cerradão woody component and verify the overlap of forest, savanna and generalist species. We conducted the vegetation survey in sites in six states: DF, MG, MS, MT, PI and TO. The cerradão did not present a homogenous structure or floristic consistency among sites, presenting itself as a heterogeneous phytophysiognomy. Structurally it presented great variations, with both open and closed formations (density 652-1732 ind. ha ${ }^{-1}$; basal area 12.83-22.45 $\mathrm{m}^{2} \mathrm{ha}^{-1}$ ). Species richness varied from 49 (MS) to 129 (MT). Floristical variation and dissimilarity was strong among the six sites with only six species occurring in all sites, where as 184 species are exclusive to one site. Although species composition is comprised of a mixture of forest and savanna species, we detected a greater participation of savanna species, with the exception of the MT site that presented a larger proportion of forest species. The general floristic and structural dissimilarity pattern observed indicate a great heterogeneity of cerradão woody flora distribution following the general patter for the Cerrado biome.
\end{abstract}

Key words: Cerrado, heterogeneity, phytosociology, savanic species, forest species

\footnotetext{
Univesidade de Brasília, Instituto de Ciências Biológicas, Departamento de Ecologia, Brasília, DF, Brasil

2 Universidade de Brasília, Faculdade de Tecnologia, Departamento de Engenharia Florestal, Brasília, DF, Brasil

3 Autor para correspondência: alexandrosol@gmail.com
} 


\section{Introdução}

Muitos estudos já demonstraram a complexidade das fisionomias vegetais do bioma Cerrado (p. ex. Coutinho 1978; Eiten 1978; Ribeiro \& Walter 2008) que reflete a grande heterogeneidade climática, edáfica e fisiográfica deste bioma (Silva et al. 2006). Uma característica inerente a essa heterogeneidade espacial do Cerrado é a fragmentação da paisagem, em lugar da descontinuidade espacial, em que as diferentes fitofisionomias ocorrem em mosaicos de manchas de diferentes tamanhos e origem (Silva et al. 2006). Portanto, a heterogeneidade espacial e a disposição em mosaico das fitofisionomias é uma característica própria do bioma, como destacado por Silva et al. (2006).

O cerradão é uma formação florestal do bioma Cerrado que apresenta cobertura arbórea de 50\% a 90\% (Ribeiro \& Walter 2008) dominado por árvores e arbustos comuns em formações savânicas mais abertas do Cerrado, formações florestais e algumas espécies generalistas (Felfili et al. 1994; Oliveira-Filho \& Ratter 1995). Nesta fitofisionomia, as árvores comumente atingem 8 a 15 m de altura, os arbustos de 2 a $5 \mathrm{~m}$ e ocorre uma camada relativamente escassa de espécies herbáceas (Goodland \& Ferri 1979; Oliveira-Filho \& Ratter 2002). O cerradão ainda pode ser identificado por outras características fisionômicas: as árvores, mesmo aquelas comuns no cerrado stricto sensu, apresentam no cerradão fuste reto e com ramificações mais altas (Waibel 1948), ritidoma mais fino, sendo menos adaptadas à passagem do fogo (Ratter 1992). Geomorfologicamente, o cerradão está associado a áreas de interflúvio dos planaltos, geralmente em local de terreno bem drenado e solos profundos (Ribeiro \& Walter, 2008). Floristicamente o cerradão compartilha maior quantidade de espécies com o cerrado sensu stricto do que com matas de galeria e matas secas (Walter 2006; Ribeiro \& Walter 2008).

Sabe-se que o bioma Cerrado vem sofrendo, desde a metade do século passado, um grave processo de degradação e intensificação do uso do solo para fins agro-pastoris e que se não forem reduzidas as taxas de desmatamento o Brasil perderá o restante da cobertura vegetal remanescente do Cerrado (cerca de 50\%) (Klink \& Machado 2005; Sano et al. 2010). Mendonça et al. (2008) divulgaram que o Cerrado tem mais de 12 mil espécies vasculares, compondo a savana mais rica do mundo e com aproximadamente 35\% de sua flora composta por espécies endêmicas, o que representa $1,5 \%$ das espécies vegetais endêmicas no mundo (Myers et al. 2000). Em virtude do grau de ameaça da riqueza florística e da quantidade de espécies endêmicas o Cerrado é apontado como um dos hotspots para a conservação da biodiversidade mundial (Myers et al. 2000; Mittermeier et al. 2005)

Os primeiros trabalhos relativos aos aspectos fisionômico-florístico do cerradão tratam da observação e da descrição das principais características estruturais (altura, densidade, estratificação etc.) bem como da composição geral das espécies, inclusive indicando as espécies mais abundantes e com portes mais elevados em diferentes fi- tofisionomias (Warming 1908; Waibel 1948; Veloso 1948; Aubréville 1959; Rizzini 1963; Magalhães 1966; Heringer et al. 1977). Os trabalhos realizados na expedição britânica Xavantina-Cachimbo (Ratter et al. 1973; 1978a; Ratter 1987; Furley \& Ratter 1988) são, na sua maioria, trabalhos qualitativos em diversas fitofisionomias, que incluem o cerradão. No entanto, alguns destes estudos exploratórios, aliados à extensa análise das propriedades do solo (Askew et al. 1970; 1971), possibilitaram a identificação de dois subtipos de cerradão: mesotrófico e distrófico (Ratter et al. 1977). Estudos que se preocuparam em evidenciar a estrutura do cerradão, a partir de parâmetros quantitativos (densidade, frequência e área basal) com o intuito de detectar padrões de dominância e importância de espécies, só foram publicados no final da década de 1970 e início da década de 1980 (Goodland \& Ferri 1979; Araújo 1984; Ribeiro et al. 1985).

Recentemente diversos trabalhos foram realizados com o objetivo de descrever a estrutura e a composição florística da vegetação lenhosa do cerradão em diversas partes do bioma (Pereira-Silva et al., 2004, São Paulo; Miranda et al., 2006, Roraima; Guilherme \& Nakajima, 2007, Minas Gerais; Silva et al., 2008, Maranhão; Kunz et al., 2009, Mato Grosso entre outros). No entanto, as diferenças em termos de padronização do esforço amostral, tamanho das unidades amostrais e critério de inclusão dificulta comparações e a emergência de um perfil florístico e estrutural para o cerradão. Com isso algumas questões relacionadas à ecologia do cerradão ainda não estão totalmente esclarecidas, como, por exemplo: o que é o cerradão, um tipo de floresta do planalto central ou uma formação savânica mais densa e pujante? Qual a variação estrutural e florística do cerradão? Como estão arranjadas e distribuídas as espécies lenhosas nas áreas de cerradão ao longo do bioma?

Nossa hipótese de trabalho é que apesar de existir um núcleo de espécies que caracterizam o cerradão, grande parte da sua flora é influenciada por biomas e vegetações associadas (florestais e savânicas) e que reflete na estrutura e composição da vegetação. Assim, este trabalho parte da premissa que o cerradão apresenta composição de espécies mista representada por espécies de formações florestais e savânica, além de espécies generalistas. Assim, é esperado que embora ocorra domínio de espécies savânicas e generalistas na flora do cerradão, devido à maior semelhança florística com as espécies lenhosas do cerrado stricto sensu, as condições ambientais favoráveis, principalmente as propriedades edáficas, promovem porte maior das mesmas e que em conjunto com as espécies florestais propiciam ao cerradão apresentar estrutura florestal. Desta forma os objetivos do presente trabalho foram: (1) descrever a composição florística e a estrutura do componente lenhoso em seis áreas de cerradão; (2) avaliar o grau de sobreposição de espécies florestais, savânicos e generalistas nas áreas analisadas e identificar as espécies que tipificam o cerradão; (3) verificar a existência de padrão de variação na estrutura da vegetação lenhosa que caracterize a fitofisionomia do cerradão. 


\section{Materiais e métodos}

\section{Áreas de estudo}

A seleção das áreas de estudo contou com auxílio de mapas e de imagens de satélite, além do apoio de pesquisadores experientes com conhecimento dos locais indicados. Ao mesmo tempo, para a escolha dos efetivos locais de amostragem foram necessárias viagens exploratórias e de reconhecimento para selecionar os fragmentos mais intactos e de tamanho desejável para a aplicação da amostragem. Para encontrar efetivas áreas da fitofisionomia cerradão utilizamos tanto o posicionamento geomorfológico quanto critérios fisionômicos, por exemplo, altura, densidade arbórea e fechamento do dossel (sensu Ribeiro \& Walter 2008) e critérios florísticos: presença de espécies típicas das formações savânicas (p. ex., Qualea grandiflora e Caryocar brasiliense), das formações florestais (p. ex., Copaifera langsdorffi, Tapirira guianensis e Protium heptaphyllum) e algumas generalistas (p. ex., Tachigali vulgaris). As áreas selecionadas para este estudo se basearam, em parte, no mapa de regiões florísticas elaborado para o cerrado stricto sensu ao longo de todo o bioma Cerrado (Ratter et al. 2003). Além da tentativa de explorar lacunas evidenciadas no referido estudo, procurando contemplar mais de uma região florística e em porções geograficamente distintas, foram selecionadas áreas situadas em diferentes Unidades Fisiográficas/ Sistemas de terra (Cochrane et al.1985) e Unidades Ecológicas (Silva et al. 2006).

Assim, o presente estudo foi realizado em seis áreas de cerradão distribuídas em porções marginais e centrais (core) do bioma Cerrado (Fig. 1 e Tab. 1): (1) Área de Relevante Interesse Ecológico (ARIE) de cerradão em Brasília, DF; (2) município de Paracatu, MG; (3) município de Dois Irmãos do Buriti, MS; (4) Parque Estadual do Araguaia, MT; (5) Parque Nacional Sete Cidades, PI; (6) município Rio da Conceição, TO. Para fins de discussão a nomenclatura das áreas será adotada doravante a sigla do estado onde foi realizado o estudo: PI, MT, TO, DF, MG e MS.

\section{Levantamento da vegetação}

Foi realizado levantamento fitossociológico da vegetação, adotando o método de parcelas, descrito em Mueller-Dombois \& Ellenberg, (1974). Foram demarcadas dez parcelas de 20 x $50 \mathrm{~m}$ em cada uma das seis áreas de cerradão amostradas, conforme metodologia descrita por Felfili et al. (2005). O método de amostragem adotado foi aleatório em grande parte dos fragmentos, no entanto, em fragmentos muito pequenos ou com dificuldade de acesso, como no caso da área PI, foi realizada amostragem sistemática com espaçamento de pelo menos $50 \mathrm{~m}$ entre cada parcela. A aleatorização foi realizada a partir do sorteio de um dos pontos de entrada no fragmento, localizado na principal via de accesso ao fragmento, em seguida sendo sorteada a distância perpendicular a ser percorrida dentro do fragmen- to a partir do ponto de entrada do fragmento (em metros, descontando o efeito de borda), conforme recomendado pelo manual de parcelas permanentes dos biomas Cerrado e Pantanal (Felfili et al. 2005).

$O$ critério de inclusão foi $\mathrm{D}_{30} \geq 5 \mathrm{~cm}$ (diâmetro a $30 \mathrm{~cm}$ do solo maior ou igual a $5 \mathrm{~cm}$ ), conforme recomendado por Felfili et al. (2005) e pela Comissão de Fitossociologia da Sociedade Brasileira de Botânica (http://www.botanica.org.br). A adoção deste critério facilitará futuras comparações com outros trabalhos desta natureza, particularmente aqueles no âmbito do Projeto Biogeografia do Bioma Cerrado (Felfili et al. 1994; Felfili \& Silva-Júnior 2001; Felfili et al. 2007).

A identificação do material botânico foi feita no campo, quando possível, ou através do uso de chaves analíticas e bibliografias especializadas, além de comparações com as coleções disponíveis nos seguintes herbários: Universidade de Brasília (UB) e herbário do Jardim Botânico do Rio de Janeiro (RB). Quando necessário, foram consultados especialistas em grupos taxonômicos específicos. $\mathrm{O}$ material testemunho foi depositado no herbário da Universidade de Brasília (UB). As famílias botânicas foram listadas com base no Angiosperm Phylogeny Group II (APG II, 2003). As sinonímias taxonômicas foram verificadas nas bases de dados virtuais do Missouri Botanical Garden (http://www. tropicos.org) e Kew Garden (http://www.theplantlist.org).

\section{Análise dos dados}

Para a análise fitossociológica adotamos as fórmulas apresentadas por Curtis \& MacIntosh $(1950 ; 1951)$ para os seguintes parâmetros: densidade (DR), frequência (FR), dominância (DoR), valor de cobertura (VC) e valor de importância (VI) (Kent \& Coker 1992). Os dados foram processados utilizando o programa Excel (do pacote Office 2003 do Windows).

Para avaliar a diversidade alfa em cada uma das seis áreas, e para fins comparativos com outros estudos, foram calculados os índices de diversidade de Shannon ( $\left.\mathrm{H}^{\prime}\right)$, de acordo com Magurran (1988) e índice de equabilidade (J'), de acordo com Pielou (1974). Foi realizado um teste t de Hutchinson (Zar 1996) para verificar se há diferenças significativas entre os valores dos índices de diveridade de Shannon entre as seis áreas. Para fins de comparação da riqueza foram realizadas curvas de rarefação (cruvas de esforço coletor) para as seis áreas, a partir das médias e intervalos de confiança a 95\% do número cumulativo de espécies (McCune \& Mefford 1997). Estes valores foram calculados para cada tamanho amostral sendo untilizadas todas as combinaçõs de parcelas possíveis.

Para análise da similaridade, foram feitas comparações quantitativas e qualitativas da dissimilaridade da vegetação entre as áreas de cerradão amostradas. Desta forma, foi adotado o índice de similaridade de Sørensen (índice qualitativo) com base na presença e na ausência de espécies (Mueller-Dombois \& Ellenberg 1974), assim como os percentuais de similaridade baseados no índice de 


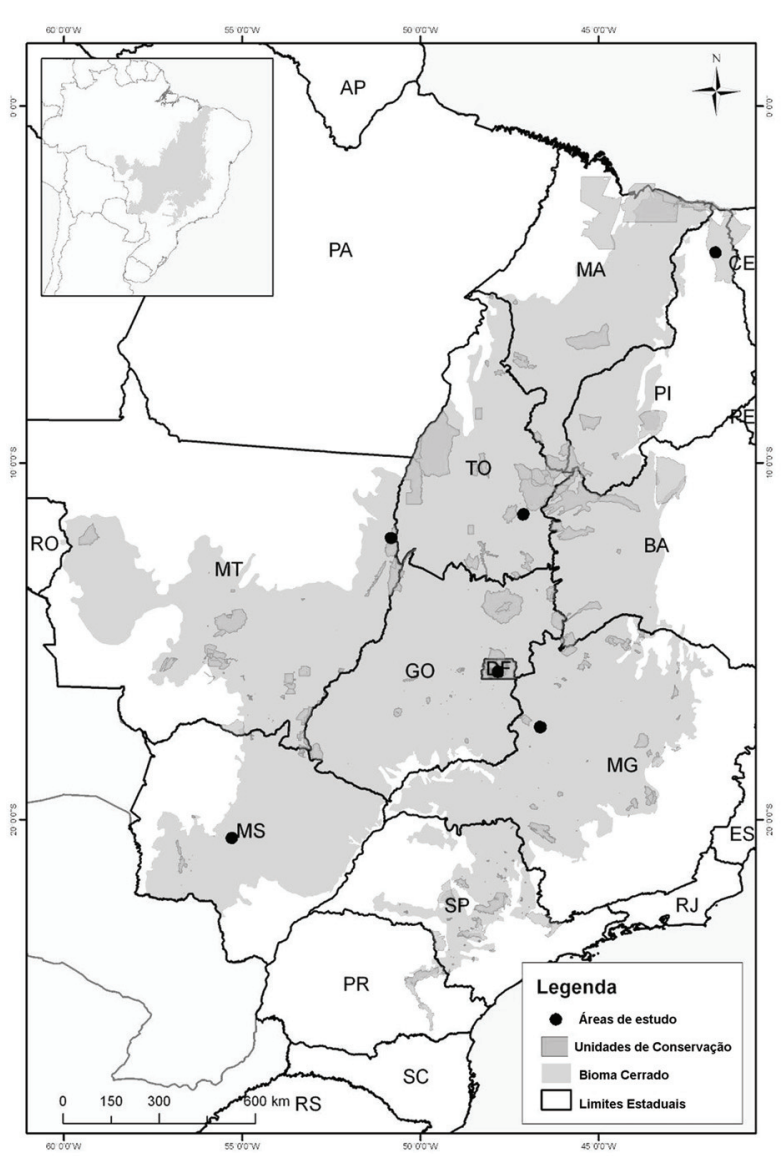

Figura 1. Localização das seis áreas de cerradão amostradas ao longo do bioma Cerrado. Com destaque para a área de abrangência do bioma e as Unidades de Conservação Federal. ARIE de Cerradão, Brasília (DF); Paracatu (MG); Dois Irmãos do Buriti (MS); Parque Estadual Araguaia (MT); Parque Nacional Sete Cidades (PI); Rio da Conceição (TO). Fonte: adaptado de IBAMA (2010).

Czekanowski (índice quantitativo) (Kent \& Coker 1992), que considera também a densidade das espécies nas áreas. Para verificar se existe influência da distância geográfica entre as áreas para os índices de similaridade foi realizado o teste de Mantel a partir do programa PC-ORD 4.0 (McCune \& Mefford 1997).

Para avaliar a natureza florística do cerradão, as espécies foram classificadas em três categorias: (1) espécies florestais, que ocorrem quase que exclusivamente em ambientes florestais (i.e. matas secas, matas de galeria e matas ciliares, sendo tolerantes à sombra e mais exigentes à umidade do solo); (2) espécies savânicas, que ocorrem quase que exclusivamente em formações savânicas (i.e. cerrado stricto sensu, campo sujo etc., sendo mais exigentes de luz e mais adaptadas à condição mais xérica) e (3) espécies generalistas amplamente distribuídas (que podem ocorrem em formações florestais e savânicas, sendo comuns ao cerradão e que apresentam ampla e abundante distribuição pelo bioma). Esta classificação foi realizada baseando-se na classificação por habitats elaborada para a flora vascular do bioma Cerrado (Mendonça et al., 2008), mas também contou com o auxílio de especialistas e observações realizadas em campo.

\section{Resultados}

As seis áreas estudadas apresentaram grande variação nos valores de área basal $\left(\mathrm{m}^{2} \mathrm{ha}^{-1}\right)$ e densidade total (ind. ha $^{-1}$ ), respectivamente: 13,44 e 1.220 (PI); 12,83 e 652 (TO); 22,45 e 1.732 (MT); 16,55 e 1.029 (MS); 22,02 e 1.435 (DF); 20,08 e 1.398 (MG) (Tab. 2). Quando incluímos outros trabalhos com critério de inclusão de $\mathrm{D}_{30}>5 \mathrm{~cm}$ e DAP $>5 \mathrm{~cm}$, o intervalo de variação para os parâmetros de área basal e densidade para o cerradão foi de 12,83 a 24,00 $\mathrm{m}^{2} \mathrm{ha}^{-1}$ e 659 a 2.170 ind. ha ${ }^{-1}$. Nota-se que a área TO do presente estudo foi a que apresentou os valores mais baixos de área basal e densidade. A área MT apresentou os maiores valores de densidade e área basal, estando entre os maiores valores para o intervalo de variação do cerradão, quando comparada a outros trabalhos no mesmo critério de inclusão.

Foi registrado nas seis áreas o total de 308 espécies (Solórzano 2011) distribuídos em 163 gêneros e 57 famílias, sendo que 246 foram identificadas no nível de espécies, 26 no nível de gênero, 20 só até família e 10 indeterminadas. Apenas 23\% das espécies ocorreram em 50\% ou mais áreas sendo que destas apenas seis espécies ocorreram nas seis: Qualea grandiflora, Qualea parviflora, Bowdichia virgilioides, Vatairea macrocarpa, Astronium fraxinifolium e Machaerium acutifolium. Onze espécies foram amostradas em cinco das seis áreas: Qualea multiflora, Pouteria ramiflora, Roupala montana, Leptolobium dasycarpum, Copaifera langsdorffi, Plathymenia reticulata, Pterodon emarginatus, Tachigali vulgaris (sinonímia de Sclerolobium paniculatum), Caryocar brasiliense, Terminalia argentea e Aspidosperma subincanum. Metade destas espécies não ocorreu na área marginal do Piauí, evidenciando ainda mais a sua flora distinta. $\mathrm{O}$ número de espécies exclusivas - isto é, que ocorreram em apenas uma das áreas amostradas - foi de 184 espécies (ca. $60 \%)$. Entre as áreas, o número de espécies exclusivas variou bastante, sendo que PI e MT apresentaram as maiores proporções e valores absolutos de espécies exclusivas (Tab. 3).

A riqueza de espécies variou bastante entre as seis áreas inventariadas, com a amplitude de variação desde 49 espécies (MS) a 124 (MT). A área de TO apresentou riqueza intermediária (77 espécies) e três áreas tiveram riqueza em torno de 100 espécies (96, 106 e 109; respectivamente PI, DF e MG). A comparação das curvas de rarefação das seis áreas (Fig. 2) indicou clara sepração da área MS, com baixa riqueza de espécies, das áreas de riqueza elevada e intermediária ( $\mathrm{MT}, \mathrm{MG}, \mathrm{DF}, \mathrm{PI}$ e TO). A partir da análise dos intervalos de confiança das curvas (95\%) as áreas amostradas apresentaram diferenças significativas nos valores de riqueza, com exceção entre as áreas MG e DF. Para facilitar a visualização do gráfico com as curvas de rarefação, foram removidos os intervalos de confiança (Fig. 2). 
Tabela 1. Síntese das áreas de estudo. Lat. = Latitude (graus decimais); Long. = Longitude (graus decimais); Alt. = altitude $(\mathrm{m}) ; \mathrm{T}=$ temperatura média anual $\left({ }^{\circ} \mathrm{C}\right)$ (fonte: INMET, 2010); P = precipitação média anual (mm) (fonte: INMET 2010; Worldclim*, Hijmans et al. 2005); UE = Unidades Ecológicas (sensu Silva et al. 2006); Pos. Geog..= posição geográfica no bioma Cerrado.

\begin{tabular}{|c|c|c|c|c|c|c|c|c|c|}
\hline Área & Local & Lat. & Long. & Alt. & $\mathrm{T}$ & $\mathrm{P}$ & UE & Sistema de terra & Pos. Geog. \\
\hline 1. DF & ARIE $^{1}$ Brasília & -15.8624 & -47.8206 & 1070 & 21 & 1500 & $1 \mathrm{~A}$ & Chapada Pratinha & Área core (centro-norte) \\
\hline 2. MG & Paracatu $^{2}$ & -17.4195 & -46.6358 & 720 & 23,5 & 1450 & $1 \mathrm{E}$ & Paracatu & Área core (central) \\
\hline 3. MS & Dois Irmão do Buriti ${ }^{3}$ & -20.5218 & -55.2739 & 260 & 23 & 1600 & $1 \mathrm{E}$ & $\begin{array}{c}\text { Planície de Campo } \\
\text { Grande }\end{array}$ & $\begin{array}{l}\text { Meridional. Perto do } \\
\text { Pantanal }\end{array}$ \\
\hline 4. MT & $\begin{array}{c}\text { Parque Estadual } \\
\text { Araguaia, Novo Santo } \\
\text { Antônio }\end{array}$ & -12.1121 & -50.8159 & 220 & $27^{*}$ & $1600^{*}$ & $4 \mathrm{~A}$ & $\begin{array}{l}\text { Depressão do } \\
\text { Araguaia }\end{array}$ & $\begin{array}{c}\text { Área core (oeste). Perto do } \\
\text { Bioma Amazônico }\end{array}$ \\
\hline 5. PI & $\begin{array}{c}\text { Parque Nacional Sete } \\
\text { Cidades, Piracuruca }\end{array}$ & -4.0979 & -41.7246 & 160 & $27,5^{*}$ & $1250^{*}$ & $3 \mathrm{D}$ & n.d. & $\begin{array}{c}\text { Marginal (nordeste). Perto } \\
\text { da Caatinga }\end{array}$ \\
\hline 6. TO & Rio da Conceição & -11.4462 & -47.1071 & 780 & 25,5 & 1500 & $2 \mathrm{C}$ & $\begin{array}{l}\text { Terras Altas de } \\
\text { Tocantins }\end{array}$ & Área core (central) \\
\hline
\end{tabular}

${ }^{1}$ Área de Relevante Interesse Ecológico e parte da dissertação de mestrado de J.S. Silva; ${ }^{2}$ Fazenda São Miguel, Área da CEMIG (Companhia de Energia do Estado de Minas Gerais) e trecho de cerradão cerca da BR-040.; ${ }^{3}$ Fazenda Taruama, da empresa de mineração MMX (do grupo EBX).

Assim como para a riqueza a análise da diversidade alfa, medida através do índice de diversidade de Shannon $\left(\mathrm{H}^{\prime}\right)$ apresentou padrão de elevados valores na região central do bioma e na região de MT. Dos cinco estudos com índice de Shannon mais elevados, quatro foram inventariados neste trabalho: MT, $(4,00)$, DF $(3,88)$, MG $(3,86)$ e PI $(3,73)$ (Tab. 2). O teste de $t$ de Hutchinson revelou que todas as áreas apresentaram índice de diversidade significativamente diferentes $(\mathrm{p}<0,01)$, com exceção de $\mathrm{DF}$ e MG que não apresentaram diferença significativa entre os valores dos seus índices de Shannon. O índice de equabilidade de Pielou variou de 0,78 na área MS a 0,83 na área TO e DF, sendo que as demais áreas apresentaram equabilidade de 0,82 . O cerradão amostrado em MS apresentou um dos menores valores de H' registrado para o cerradão $(3,06)$, sendo reflexo de sua baixa riqueza (49 espécies) e baixa equabilidade $(0,78)$.

A análise de similaridade de Sørensen e de Czekanowski indicou baixa similaridade entre as seis áreas $(<50 \%)$, ou seja, florísticamente complementares (Tab. 4). Apenas entre MG e TO (Sørensen $=0,58)$ e entre MG e DF (Sørensen = 0,54 ) houve algum grau de similaridade. Em geral, MG foi a que apresentou maior similaridade com as demais áreas, tanto em termos qualitativos quanto quantitativos. $\mathrm{O}$ teste de Mantel para as medidas de similaridade de Sørensen e Czekanowski indicou influência da distância geográfica entre as áreas no resultados de similaridade $(\mathrm{p}>0,05)$.

Do total de espécies amostradas nas seis áreas 124 (40\%) foram classificadas como espécies de formações florestais do bioma Cerrado (i.e. matas de galeria, matas secas e matas ciliares), 105 (33,5\%) classificadas de formações savânicas (i.e. cerrado lato sensu, mas especialmente pertencente ao cerrado stricto sensu), 20 (6,5\%) classificadas como generalistas de habitat (ocorrendo amplamente em formações florestais e savânicas do Cerrado) e 61 espécies (20\%) não foram classificadas ou por não estar presente na lista de Mendonça et al. (2008) ou por não ter sido identificado até o nível de espécie. Com exceção da área MT, todas as áreas apresentaram maior número de espécies savânicas do que florestais: nas áreas DF e MG a quantidade de espécies florestais foi elevada, próximo ao número de espécies savânicas; nas áreas MS, PI e TO o domínio na categoria savânico foi mais pronunciado sendo que na área PI houve mais do dobro de espécies savânicas em relação às espécies florestais. Para o caso da área PI o número de espécies sem classificação, em função da quantidade de espécies que não foram classificadas até o nível de espécie, pode ter influenciado os resultados (Tab. 5).

O número de espécies para perfazer $50 \%$ do valor de importância em cada uma das áreas variou bastante, desde sete espécies para MS até 20 espécies para MT e com valores intermediários para DF, MG e PI com 14 espécies e TO com 10 (Tab. 6). Analisando a participação das diferentes categorias de espécies de acordo com sua preferência por habitat para as espécies que somaram 50\% do IVI (Tab. 7) notam-se três padrões distintos: (1) equilíbrio entre as categorias florestal e savânica, nas áreas MG, MS e TO; (2) predomínio de espécies florestais, na área MT e (3) predomínio de espécies savânicas, na área PI e DF. Nas seis áreas, a categoria generalistas ocorreu com uma ou duas espécies (ou nenhuma no caso de MS).

As espécies que apresentaram as densidades mais elevadas ( $>50$ ind.) em pelo menos uma das seis áreas foram: Qualea grandiflora, Copaifera langsdorffi, Tachigali vulgaris, Emmotum nitens, Simarouba versicolor, Ouratea hexasperma, Terminalia fagifolia, Xylopia aromatica, Miconia burchelli, Ocotea pomaderroides, Astronium fraxinifolium, Cordiera macrophylla, Vatairea macrocarpa, Bauhinia rufa, Buchenavia tomentosa, Ephedranthus pisocarpus, Copaifera coriacea, Campomanesia aromatica, Protium heptaphyllum, Maprounea guianensis, Hirtella glandulosa, Matayba guianensis e Myrcia sellowiana. As seguintes espécies apresentaram elevado valor de importância em mais de uma área estudada: Qualea grandiflora, Emmotum nitens, Copaifera 
Tabela 2. Parâmetros estruturais e de diversidade em áreas de cerradão organizados a partir do critério de inclusão. Onde: Solo se refere ao subtipo de cerradão: Dis = cerradão distrófico e Mes = cerradão mesotrófico; Diam. $=$ critério de inclusão: $\mathrm{D}_{30}=$ diâmetro a $30 \mathrm{~cm}$ do solo; $\mathrm{DAP}=$ diâmetro à altura do peito $(1,30 \mathrm{~cm}$ do solo); DAS = diâmetro à altura do solo; Área = área amostral (ha). Parcela = tamanho das parcelas (m); $\mathrm{S}=$ riqueza de espécies; $\left(\mathrm{H}^{\prime}\right)=$ índice de diversidade de Shannon $\left(\right.$ nats ind ${ }^{-1}$.); $\left(\mathrm{J}^{\prime}\right)=$ índice de Equabilidade de Pielou; DTA = densidade total por área (ind. ha $\left.{ }^{-1}\right) ; \mathrm{AB}=$ área basal total por área $\left(\mathrm{m}^{2}\right.$ ha $\left.{ }^{-1}\right) ; n . d .=$ não disponível.

\begin{tabular}{|c|c|c|c|c|c|c|c|c|}
\hline Local (Autor) & Solo $^{*}$ & Diam. & $\begin{array}{l}\text { Área (ha) } \\
\text { Pacela }\end{array}$ & S & $\mathrm{H}^{\prime}$ & $\mathrm{J}^{\prime}$ & DTA & $\mathrm{AB}\left(\mathrm{m}^{2} / \mathrm{ha}\right)$ \\
\hline $\begin{array}{l}\text { PNSC, PI } \\
\text { Este estudo }\end{array}$ & Dis & $\mathrm{D}_{30} \geq 5 \mathrm{~cm}$ & $\begin{array}{c}1,0 \\
(20 \times 50 \mathrm{~m})\end{array}$ & 95 & 3,73 & 0,81 & 1.220 & 13,44 \\
\hline $\begin{array}{l}\text { Rio da Conceição, TO } \\
\text { Este estudo }\end{array}$ & Dis & $\mathrm{D}_{30} \geq 5 \mathrm{~cm}$ & $\begin{array}{c}1,0 \\
(20 \times 50 \mathrm{~m})\end{array}$ & 77 & 3,61 & 0,83 & 652 & 12,83 \\
\hline $\begin{array}{l}\text { ARIE Cerradão, Brasília, DF } \\
\text { Este estudo }\end{array}$ & Dis & $\mathrm{D}_{30} \geq 5 \mathrm{~cm}$ & $\begin{array}{c}1,0 \\
(20 \times 50 \mathrm{~m})\end{array}$ & 106 & 3,85 & 0,82 & 1.493 & 20,08 \\
\hline $\begin{array}{l}\text { Paracatu, MG } \\
\text { Este estudo }\end{array}$ & Dis & $\mathrm{D}_{30} \geq 5 \mathrm{~cm}$ & $\begin{array}{c}1,0 \\
(20 \times 50 \mathrm{~m})\end{array}$ & 109 & 3,86 & 0,82 & 1.398 & 22,75 \\
\hline $\begin{array}{l}\text { PEA, MT } \\
\text { Este estudo }\end{array}$ & Dis & $\mathrm{D}_{30} \geq 5 \mathrm{~cm}$ & $\begin{array}{c}1,0 \\
(20 \times 50 \mathrm{~m})\end{array}$ & 124 & 4,00 & 0,82 & 1.732 & 22,45 \\
\hline $\begin{array}{l}\text { Dois Irmãos do Buriti, MS } \\
\text { Este estudo }\end{array}$ & Dis & $\mathrm{D}_{30} \geq 5 \mathrm{~cm}$ & $\begin{array}{c}1,0 \\
(20 \times 50 \mathrm{~m})\end{array}$ & 49 & 3,06 & 0,79 & 1.029 & 16,55 \\
\hline $\begin{array}{l}\text { Nova Xavantina, MT } \\
\text { (Franczak, 2006) }\end{array}$ & Dis & $\mathrm{D}_{30} \geq 5 \mathrm{~cm}$ & $\begin{array}{c}0,5 \\
(10 \times 10 \mathrm{~m})\end{array}$ & 95 & 3,69 & 0,81 & 2.178 & 23,51 \\
\hline $\begin{array}{l}\text { Nova Xavantina, MT } \\
\text { (Marimon-Júnior \& Haridisan, 2005) }\end{array}$ & Dis & $\mathrm{D}_{30} \geq 5 \mathrm{~cm}$ & $\begin{array}{c}0,5 \\
(10 \times 10 \mathrm{~m})\end{array}$ & 77 & 3,67 & 0,84 & 1.884 & 21,38 \\
\hline $\begin{array}{l}\text { CPAC-Planaltina, DF } \\
\text { (Felfili et al., 1994) }\end{array}$ & Dis & $\mathrm{D}_{30} \geq 5 \mathrm{~cm}$ & $\begin{array}{c}0,4 \\
(20 \times 50 \mathrm{~m})\end{array}$ & 55 & 3,08 & n.d. & 1.263 & 23,38 \\
\hline $\begin{array}{l}\text { APA Gama-Cabeça de Veado, DF } \\
\text { (Felfili et al., 1994) }\end{array}$ & Dis & $\mathrm{D}_{30} \geq 5 \mathrm{~cm}$ & $\begin{array}{c}0,4 \\
(20 \times 50 \mathrm{~m})\end{array}$ & 51 & 3,17 & n.d. & 960 & 24,00 \\
\hline $\begin{array}{l}\text { Paracatu, MG } \\
\text { (Felfili et al.,1994) }\end{array}$ & Dis & $\mathrm{D}_{30} \geq 5 \mathrm{~cm}$ & $\begin{array}{c}0,4 \\
(20 \times 50 \mathrm{~m})\end{array}$ & 81 & 3,21 & n.d. & 1.382 & 18,03 \\
\hline $\begin{array}{l}\text { Patrocínio, MG } \\
\text { (Felfili } \text { et al., 1994) }\end{array}$ & Dis & $\mathrm{D}_{30} \geq 5 \mathrm{~cm}$ & $\begin{array}{c}0,4 \\
(20 \times 50 \mathrm{~m})\end{array}$ & 65 & 3,65 & n.d. & 1.407 & 17,47 \\
\hline $\begin{array}{l}\text { Silvânia, GO } \\
\text { (Felfili et al., 1994) }\end{array}$ & Mes & $\mathrm{D}_{30} \geq 5 \mathrm{~cm}$ & $\begin{array}{c}0,4 \\
(20 \times 50 \mathrm{~m})\end{array}$ & 89 & 3,56 & n.d. & 2.082 & 21,64 \\
\hline $\begin{array}{l}\text { Alto Paraíso, GO } \\
\text { (Felfili } \text { et al., 2007) }\end{array}$ & Mes & $\mathrm{D}_{30} \geq 5 \mathrm{~cm}$ & $\begin{array}{c}0,3 \\
(20 \times 50 \mathrm{~m})\end{array}$ & 39 & 3,23 & n.d. & 716 & 16,67 \\
\hline $\begin{array}{l}\text { Vila Propício, GO } \\
\text { (Felfili et al., 2007) }\end{array}$ & Dis & $\mathrm{D}_{30} \geq 5 \mathrm{~cm}$ & $\begin{array}{c}0,2 \\
(20 \times 50 \mathrm{~m})\end{array}$ & 57 & 3,50 & n.d. & 1.440 & 23,11 \\
\hline $\begin{array}{l}\text { Uberlândia, MG Cerradão } 1 \\
\text { (Guilherme \& Nakajima, 2007) }\end{array}$ & Dis & $\mathrm{DAP} \geq 5 \mathrm{~cm}$ & $\begin{array}{c}0,35 \\
(10 \times 10 \mathrm{~m})\end{array}$ & 56 & 2,92 & 0,81 & 1.117 & 19,30 \\
\hline $\begin{array}{l}\text { Uberlândia, MG } \\
\text { (Costa \& Araújo, 2001) }\end{array}$ & Dis & $\mathrm{DAP} \geq 5 \mathrm{~cm}$ & $\begin{array}{c}1,0 \\
(20 \times 20 \mathrm{~m})\end{array}$ & 93 & 3,54 & 0,78 & 2.071 & 17,06 \\
\hline $\begin{array}{l}\text { Bandeirante, MS } \\
\text { (Camilotti, 2006) }\end{array}$ & Dis & $\mathrm{DAP} \geq 5 \mathrm{~cm}$ & $\begin{array}{c}1,0 \\
(25 \times 25 \mathrm{~m})\end{array}$ & 82 & 3,08 & 0,78 & 2.118 & 23,51 \\
\hline $\begin{array}{l}\text { Ribeirão Cascalheira, MT - Cerradão } 1 \\
\text { (Marimon et al., 2006) }\end{array}$ & Dis & $\mathrm{DAP} \geq 5 \mathrm{~cm}$ & $\begin{array}{c}0,1 \\
(10 \times 20 \mathrm{~m})\end{array}$ & 49 & 3,38 & 0,87 & 2.130 & 18,05 \\
\hline $\begin{array}{l}\text { Ribeirão Cascalheira, MT - Cerradão } 2 \\
\text { (Marimon et al., 2006) }\end{array}$ & Dis & $\mathrm{DAP} \geq 5 \mathrm{~cm}$ & $\begin{array}{c}0,1 \\
(10 \times 20 \mathrm{~m})\end{array}$ & 51 & 3,50 & 0,89 & 1.850 & 13,31 \\
\hline $\begin{array}{l}\text { Canarana, MT } \\
\text { (Kunz et al., 2009) }\end{array}$ & n.d. & $\mathrm{DAS} \geq 5 \mathrm{~cm}$ & $\begin{array}{c}1,0 \\
(20 \times 50)\end{array}$ & 95 & 3,85 & 0,84 & 2.381 & 24,75 \\
\hline $\begin{array}{l}\text { Fazenda Salina, Pantanal 1, MS } \\
\text { (Dubs, 1992) }\end{array}$ & Mes & $\mathrm{DAP} \geq 10 \mathrm{~cm}$ & $\begin{array}{c}0,18 \\
(10 \times 60 \mathrm{~m})\end{array}$ & 25 & n.d. & n.d. & 438 & 13,35 \\
\hline $\begin{array}{l}\text { Fazenda Salina, Pantanal 2, MS } \\
\text { (Dubs, 1992) }\end{array}$ & Mes & $\mathrm{DAP} \geq 10 \mathrm{~cm}$ & $\begin{array}{c}1,0 \\
(20 \times 100 \mathrm{~m})\end{array}$ & 42 & n.d. & n.d. & 306 & 11,08 \\
\hline $\begin{array}{l}\text { Fazenda Salina, Pantanal 3, MS } \\
\text { (Dubs, 1992) }\end{array}$ & Mes & $\mathrm{DAP} \geq 10 \mathrm{~cm}$ & $\begin{array}{c}0,18 \\
(10 \times 60 \mathrm{~m})\end{array}$ & 30 & n.d. & n.d. & 516 & 15,64 \\
\hline $\begin{array}{l}\text { Brotas, SP } \\
\text { (Gomes et al., 2004) }\end{array}$ & Dis & $\mathrm{DAS} \geq 3 \mathrm{~cm}$ & $\begin{array}{c}1,0 \\
(10 \times 10 \mathrm{~m})\end{array}$ & 125 & 3,37 & n.d. & 3.787 & -- \\
\hline $\begin{array}{l}\text { CPAC-Planaltina, DF } \\
\text { (Ribeiro et al., 1985) }\end{array}$ & Dis & $\mathrm{DAP} \geq 3 \mathrm{~cm}$ & $\begin{array}{c}0,225 \\
(20 \times 50 \mathrm{~m})\end{array}$ & 81 & n.d. & n.d. & 2.231 & 22,90 \\
\hline
\end{tabular}


Tabela 2. Continuação.

\begin{tabular}{|c|c|c|c|c|c|c|c|c|}
\hline Local (Autor) & Solo* & Diam. & $\begin{array}{l}\text { Área (ha) } \\
\text { Pacela }\end{array}$ & S & $\mathrm{H}^{\prime}$ & $J^{\prime}$ & DTA & $\mathrm{AB}\left(\mathrm{m}^{2} / \mathrm{ha}\right)$ \\
\hline $\begin{array}{l}\text { Poconé, MT } \\
\text { (Guarim et al., 2000) }\end{array}$ & Mes & $\mathrm{DAP} \geq 3 \mathrm{~cm}$ & $\begin{array}{c}1,0 \\
(10 \times 10 \mathrm{~m})\end{array}$ & 33 & n.d. & n.d. & 869 & 4,74 \\
\hline $\begin{array}{l}\text { Vilhena, RO } \\
\text { (Miranda et al., 2006) }\end{array}$ & Dis & $\mathrm{CAS} \geq 10 \mathrm{~cm}$ & $\begin{array}{c}1,0 \\
(10 \times 1.000 \mathrm{~m})\end{array}$ & 60 & 3,45 & 0,84 & 1.398 & 12,44 \\
\hline $\begin{array}{l}\text { Luiz Antônio, SP } \\
\text { (Pereira-Silva et al., 2004) }\end{array}$ & Dis & $\mathrm{DAS} \geq 1 \mathrm{~cm}$ & $\begin{array}{c}0,625 \\
(10 \times 25 \mathrm{~m})\end{array}$ & 121 & 3,47 & 0,40 & 8.454 & 24,64 \\
\hline $\begin{array}{l}\text { Urbano Santos, MA } \\
\text { (Silva et al., 2008) }\end{array}$ & n.d. & $\mathrm{DAS} \geq 1 \mathrm{~cm}$ & $\begin{array}{l}133 \text { pontos } \\
(10 \mathrm{~m})^{\star *}\end{array}$ & 69 & 3,31 & 0,78 & 2.790 & n.d. \\
\hline $\begin{array}{l}\text { CPAC-Planaltina, DF } \\
\text { (Ribeiro, 1983) }\end{array}$ & Dis & $\mathrm{DAP} \geq 3 \mathrm{~cm}$ & $\begin{array}{l}80 \text { pontos } \\
(10 \mathrm{~m})^{* *}\end{array}$ & 61 & n.d. & n.d. & 1.864 & 17,90 \\
\hline $\begin{array}{l}\text { Padre Bernardo, GO } \\
\text { (Araújo, 1984) }\end{array}$ & Mes & $\mathrm{DAP} \geq 10 \mathrm{~cm}$ & $\begin{array}{l}53 \text { pontos } \\
(10 \mathrm{~m})^{* *}\end{array}$ & 39 & n.d. & n.d. & 1.098 & 23,10 \\
\hline $\begin{array}{l}\text { Brasília, DF } \\
\text { (Araújo, 1984) }\end{array}$ & Dis & $\mathrm{DAP} \geq 10 \mathrm{~cm}$ & $\begin{array}{l}55 \text { pontos } \\
(15 \mathrm{~m})^{* *}\end{array}$ & 39 & n.d. & n.d. & 1.336 & 21,54 \\
\hline
\end{tabular}

*A classificação dos solos (mestrófico e distrófico) baseado nas indicações dos próprios autores, em análises de solos contidos nos trabalhos, ou na presença de espécies indicadoras destes solos.

** método ponto quadrantes (distância dos pontos)

langsdorffi e Tachigali vulgaris. Destacam-se também espécies que apresentaram elevada importância em apenas uma das áreas inventariadas: Ocotea pomaderroides e Simarouba versicolor (DF); Xylopia aromatica (MG); Vatairea macrocarpa (MS); Protium heptaphyllum e Hirtella glandulosa (MT); Terminalia fagifolia e Copaifera coriacea (PI); Tapirira guianensis (TO).

\section{Discussão}

As seis áreas de cerradão inventariadas não se mostraram estruturalmente homogêneas, havendo grandes variações nos parâmentros de área basal e densidade de indivíduos. Assim, na área MT, o porte maior do cerradão pode estar relacionado com a influencia florística de espécies amazônicas dada a sua proximidade geográfica. Já as áreas PI e TO apresentam menor densidade e área basal e, portanto, estrutura mais aberta. Este padrão é esperado para o cerradão do Piauí, que já foi descrito como um "cerradão de cerrado" no sentido de serem etruturalmente mais próximo ao cerrado stricto sensu do que os cerradões da região central e sul (Castro \& Martins 1999). Portanto a heterogeneidade estrutural pode estar associada a variações regionais do cerradão.
O resultado de riqueza total das seis áreas de cerradão (308 espécies) está bem próximo ao valor encontrado por Oliveira-Filho \& Ratter (1995) de 321 espécies inventariadas em 15 áreas de cerradão em estudo fitogeográfico das formações florestais do bioma Cerrado. Na comparação com outras formações florestais, a riqueza do cerradão apenas superou a riqueza inventariada para florestas estacionais deciduais (276 espécies inventariadas em 18 áreas) (Oliveira-Filho \& Ratter 1995). Ao mesmo tempo, na comparação com outros inventários de cerradão, quatro das seis áreas aqui estudadas (PI, DF, MG e MT) apresentaram valores de riqueza superiores ao encontrado em outros estudos (ver Tab. 2). O que pode estar influenciando a elevada riqueza é o intercambio contínuo do cerradão com a flora das formações savânicas e florestais que as circundam (Oliveira-Filho \& Ratter 1995). Em relação aos índices de diversidade de Shannon e equabilidade de Pielou o padrão foi o mesmo que o observado para a riqueza de espécies, ou seja, com exceção da área de MS, as áreas amostradas no presente estudo apresentam elevados valores em ambos os índices, indicando além da elevada riqueza, uma distribuição equilibrada de indivíduos entre as espécies (Magurran 1988). As análises de teste $t$ de Hutchinson para os índices de diversidade e as curvas de rarefação confirmaram esse padrão de baixa riqueza e diversidade da área MS em contraste com os

Tabela 3. Número de espécies arbóreas (DAS $\geq 5 \mathrm{~cm}$ ) e proporção de espécies exclusivas nas seis áreas de cerradão inventariadas (10 parcelas de $20 \mathrm{x} 50 \mathrm{~m}$ em cada área). ARIE de Cerradão, Brasília (DF); Paracatu (MG); Dois Irmãos do Buriti (MS); Parque Estadual Araguaia (MT); Parque Nacional Sete Cidades (PI); Rio da Conceição (TO).

\begin{tabular}{|c|c|c|c|c|c|c|}
\hline & $\mathrm{DF}$ & MG & MS & MT & PI & TO \\
\hline Número de espécies & 106 & 109 & 49 & 124 & 95 & 77 \\
\hline Espécies exclusivas & 35 & 13 & 10 & 55 & 61 & 8 \\
\hline Proporção de espécies exclusivas (\%) & 33 & 12 & 20 & 44 & 64 & 10 \\
\hline
\end{tabular}




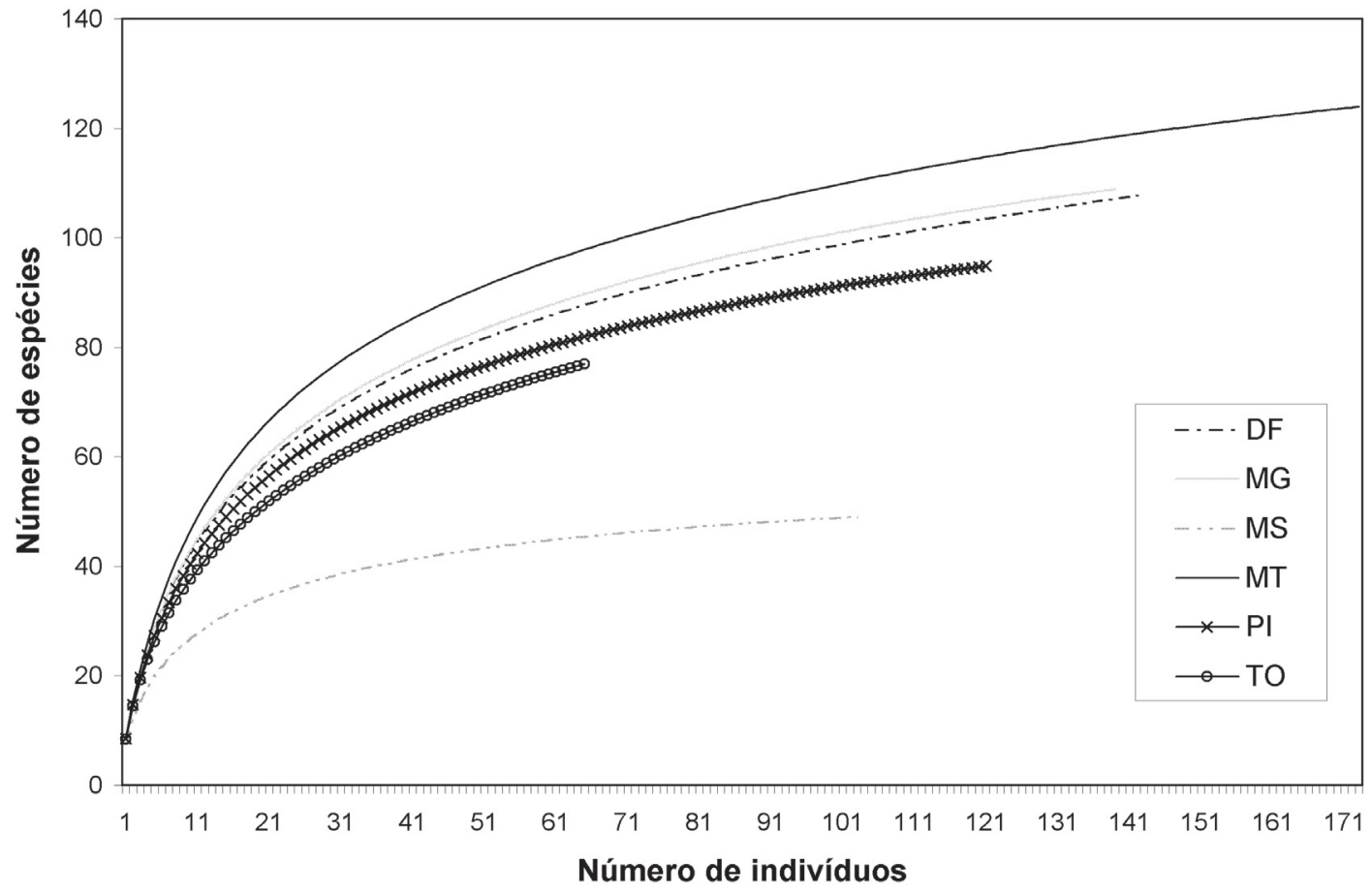

Figura 2. Curva de rarefação do número médio de espécies por número de indivíduos para o estrato arbóreo nas seis áreas de cerradão amostradas. ARIE de Cerradão, Brasília (DF); Paracatu (MG); Dois Irmãos do Buriti (MS); Parque Estadual Araguaia (MT); Parque Nacional Sete Cidades (PI); Rio da Conceição (TO).

Tabela 4. Similaridade florística entre as seis áreas de cerradão inventariadas. Os valores acima da diagonal são referentes ao índice de Czekanowski e abaixo referentes ao índice de Sørensen.

\begin{tabular}{cccccccc}
\hline & \multicolumn{7}{c}{ Czekanowski } \\
\cline { 3 - 8 } & & DF & MG & MS & MT & PI & TO \\
\cline { 3 - 8 } & DF & & 37.35 & 16.45 & 13.58 & 13.04 & 21.58 \\
\multirow{5}{*}{ Sørensen } & MG & 0.54 & & 33.98 & 27.35 & 16.58 & 33.79 \\
& MS & 0.29 & 0.42 & & 12.15 & 10.84 & 23.65 \\
& MT & 0.29 & 0.45 & 0.26 & & 13.15 & 24.69 \\
& PI & 0.18 & 0.21 & 0.16 & 0.21 & & 15.62 \\
& TO & 0.39 & 0.58 & 0.33 & 0.39 & 0.17 & \\
\hline
\end{tabular}

Tabela 5. Classificação das espécies arbóreas (DAS $\geq 5 \mathrm{~cm}$ ) registradas nas seis áreas de cerradão amostradas (10 parcelas de 20 x $50 \mathrm{~m}$ em cada área). ARIE de Cerradão, Brasília (DF); Paracatu (MG); Dois Irmãos do Buriti (MS); Parque Estadual Araguaia (MT); Parque Nacional Sete Cidades (PI); Rio da Conceição (TO). Valores representam o número total de espécies em cada categoria e entre parêntese o valor percentual.

\begin{tabular}{lcccccc}
\hline Categoria & DF & MG & MS & MT & PI & TO \\
\hline Floresta & $45(42)$ & $46(42)$ & $18(37)$ & $59(47)$ & $14(15)$ & $29(38)$ \\
Savana & $58(54)$ & $51(47)$ & $25(51)$ & $41(32)$ & $34(36)$ & $39(51)$ \\
Generalista & $4(4)$ & $10(9)$ & $2(4)$ & $6(5)$ & $11(12)$ & $9(12)$ \\
n.d. & & $2(2)$ & $4(8)$ & $18(17)$ & $36(38)$ & \\
Total & 106 & 109 & 49 & 124 & 95 & 77 \\
\hline
\end{tabular}

elevados valores de riqueza e diversidade das demais áreas.

O elevado percentual de espécies exclusivas, i.e. que ocorreu em apenas uma das áreas (60\%), superou os valores encontrados em estudos fitogeográficos do cerrado lato sensu (entorno de 40\%) (Bridgewater et al. 2004; Castro et al. 1998). Podemos atribuir este maior percentual de espécies exclusivas ao número reduzido de áreas estudadas, pois um número maior de áreas de estudo aumentaria a chance das espécies serem amostradas em múltiplos locais. Apesar desta limitação verificamos que existe grande variação da distribuição de espécies nas seis áreas de cerradão, seguindo o padrão local (i.e. característico de cada área), ou seja, um componente geográfico local que se reflete na heterogeneidade da flora lenhosa do cerrado lato sensu (Castro \& Martins 1999). Esta quantidade de espécies exclusivas pode ser atribuída à elevada heterogeneidade ambiental atribuída ao bioma Cerrado que abrange ampla variação nos fatores fisiográficos (relevo, altitude, solo) e climáticos (Silva et al. 2006), gerando um claro padrão de variação florística para o componente lenhoso do Cerrado (Castro et al. 1998; Ratter et al. 2003).

A quantidade de espécies exclusivas na área PI (69\%) reforça a ideia de que os cerrados do Nordeste apresentam caráter marginal (Castro \& Martins 1999), com grande quantidade de espécies restritas a esta região e intercâmbio de espécies com a Caatinga. Assim, Castro \& Martins (1999) chamam a atenção para dois tipos de cerradões fitogeografi- 
Tabela 6. Espécies arbóreas $\left(\mathrm{D}_{30} \geq 5 \mathrm{~cm}\right)$ que somaram mais de $50 \%$ do Valor de Importância (VI) em cada uma das seis áreas de cerradão inventariadas (10 parcelas de 20 x 50 m em cada área), com a sua respectiva classificação quanto a preferência por habitat. ARIE de Cerradão, Brasília (DF); Paracatu (MG); Dois Irmãos do Buriti (MS); Parque Estadual Araguaia (MT); Parque Nacional Sete Cidades (PI); Rio da Conceição (TO). Os valores representam o VI e entre parênteses está a posição hierárquica das espécies no ranque do VI na comunidade. Valores em negrito representam as espécies que compõem $50 \%$ do VI em cada área.

\begin{tabular}{|c|c|c|c|c|c|c|c|}
\hline \multirow{2}{*}{ Espécies } & \multirow{2}{*}{ Habitat } & \multicolumn{5}{|c|}{ VI } & \multirow[b]{2}{*}{ TO } \\
\hline & & DF & MG & MS & MT & PI & \\
\hline Emmotum nitens (Benth.) Miers & florestal & $23.84(1)$ & $17.24(3)$ & & $4.54(16)$ & & $14.05(5)$ \\
\hline Qualea grandiflora Mart. & savânica & $19.99(2)$ & $19.54(2)$ & $26.9(3)$ & $6.83(10)$ & $10.76(5)$ & $20.15(2)$ \\
\hline Ocotea pomaderroides (Meisn.) Mez & florestal & $17.18(3)$ & & & & & \\
\hline Simarouba versicolor A.St.-Hi & generalista & $11.37(4)$ & $10.83(6)$ & & $2.9(34)$ & $6.02(12)$ & \\
\hline Miconia burchellii Triana & savânica & $10.85(5)$ & & & & & \\
\hline Blepharocalyx salicifolius (Kunth) O. Berg & savânica & $10.4(6)$ & $3.86(22)$ & & & & \\
\hline Terminalia fagifolia Mart. & savânica & $10.24(7)$ & & $3.49(23)$ & & $19.25(2)$ & \\
\hline Siphoneugena densiflora O.Berg & savânica & $8.69(8)$ & & & & & \\
\hline Ouratea hexasperma (A. St.-Hil.) Baill. & savânica & $7.58(9)$ & $0.74(76)$ & & & & $10.1(10)$ \\
\hline Dalbergia miscolobium Benth. & savânica & $7.18(10)$ & $0.51(84)$ & $0.58(49)$ & & & \\
\hline Ocotea spixiana (Nees) Mez & florestal & $7.02(11)$ & $2.79(29)$ & & & & \\
\hline Schefflera macrocarpa (Cham. \& Schltdl.) Frodin & savânica & $6.94(12)$ & & & & & \\
\hline Copaifera langsdorffii Desf. & florestal & $6.38(13)$ & $24.56(1)$ & $35.39(2)$ & $4.52(18)$ & & $28.45(1)$ \\
\hline Xylopia sericea A. St.-Hil. & florestal & $6.03(14)$ & $0.88(69)$ & & & & \\
\hline Tachigali vulgaris L.G.Silva \& H.C.Lima & generalista & $1(66)$ & $12.33(4)$ & & $8.5(6)$ & $23.31(1)$ & $7.12(11)$ \\
\hline Xylopia aromatica A. St.-Hil. & florestal & $0.71(74)$ & $12.29(5)$ & & $8.03(8)$ & & $10.14(9)$ \\
\hline Dipteryx alata Vogel & savânica & & $10.1(7)$ & $10.51(9)$ & $4.54(17)$ & & \\
\hline Astronium fraxinifolium Schott ex Spreng. & florestal & $0.33(103)$ & $9.78(8)$ & $2.38(30)$ & $1.21(64)$ & $2.44(38)$ & $1.52(42)$ \\
\hline Qualea parviflora Mart. & savânica & $3.44(26)$ & $7.82(9)$ & $3.88(21)$ & $1.93(52)$ & $5.61(15)$ & $5.19(19)$ \\
\hline Cordiera macrophylla (K. Schum.) Kuntze & florestal & $1.94(39)$ & $7.36(10)$ & & $0.31(121)$ & & $1.73(37)$ \\
\hline Vatairea macrocarpa (Benth.) Ducke. & savânica & $0.37(88)$ & $6.17(11)$ & $36.98(1)$ & $3.03(33)$ & $4.75(19)$ & $2.26(31)$ \\
\hline Machaerium acutifolium Vogel & savânica & $1.5(49)$ & $5.12(12)$ & $11.82(8)$ & $0.73(81)$ & $1.98(42)$ & $2.15(32)$ \\
\hline Platypodium elegans Vogel & florestal & $0.33(101)$ & $5.01(13)$ & & & & \\
\hline Bowdichia virgilioides Kunth & savânica & $2.88(29)$ & $4.78(14)$ & $2.81(27)$ & $0.79(79)$ & $1.24(53)$ & $0.64(61)$ \\
\hline Buchenavia tomentosa Eichler & florestal & & $0.45(93)$ & $14.49(4)$ & $0.33(113)$ & & \\
\hline Anadenanthera peregrina (L.) Speg. & florestal & & & $14.3(5)$ & & & \\
\hline Bauhinia rufa (Bong.) Steud. & savânica & & & $13.66(6)$ & & & \\
\hline Pterodon emarginatus Vogel & savânica & $4.16(22)$ & $2.65(33)$ & $13.61(7)$ & $0.63(88)$ & $1.6(49)$ & \\
\hline Protium heptaphyllum (Aubl.) Marchand & florestal & & $1.53(54)$ & & $25.82(1)$ & & $6.63(13)$ \\
\hline Hirtella glandulosa Spreng. & florestal & & $1.67(52)$ & & $11.89(2)$ & & $4.24(22)$ \\
\hline Maprounea guianensis Aubl. & generalista & $1.56(47)$ & $0.87(70)$ & & $10.88(3)$ & & \\
\hline Myrcia splendens (Sw.) DC. & florestal & $4.5(19)$ & $3.42(25)$ & & $8.95(4)$ & & $5.21(18)$ \\
\hline Physocalymma scaberrimum Pohl & savânica & & & & $8.92(5)$ & & \\
\hline Vochysia haenkeana Mart. & florestal & & & & $8.12(7)$ & & $3.41(25)$ \\
\hline Matayba guianensis Aubl. & florestal & & $3.86(21)$ & & $7.46(9)$ & & $0.59(63)$ \\
\hline Virola sebifera Aubl. & florestal & $4.79(18)$ & $1.2(63)$ & & $5.47(11)$ & & \\
\hline Nectandra cuspidata Nees \& Mart. & florestal & & & & $5.38(12)$ & & \\
\hline Coussarea hydrangeifolia (Benth.) Müll. Arg. & florestal & & & & $5.26(13)$ & & \\
\hline Syagrus flexuosa (Mart.) Becc. & savânica & & $4.12(18)$ & & $4.64(14)$ & & \\
\hline Guapira graciliflora (Mart. ex J.A.Schmidt) Lundell & florestal & $1.44(51)$ & $0.42(98)$ & & $4.59(15)$ & & $0.78(54)$ \\
\hline Cenostigma macrophyllum Tul. & florestal & & & & $4.3(19)$ & & \\
\hline $\begin{array}{l}\text { Himatanthus sucuuba (Spruce ex Müll.Arg.) } \\
\text { Woodson }\end{array}$ & florestal & & & & $4.28(20)$ & & \\
\hline
\end{tabular}


Tabela 6. Continuação.

\begin{tabular}{|c|c|c|c|c|c|c|c|}
\hline \multirow{2}{*}{ Espécies } & \multirow{2}{*}{ Habitat } & \multicolumn{5}{|c|}{ VI } & \multirow[b]{2}{*}{ TO } \\
\hline & & DF & MG & MS & MT & PI & \\
\hline Copaifera coriacea Mart. & savânica & & & & & $16.15(3)$ & \\
\hline Ephedranthus pisocarpus R.E. Fr. & florestal & & & & & $15.77(4)$ & \\
\hline Anacardium occidentale L. & savânica & & & & $0.62(89)$ & $9.03(6)$ & $1.13(51)$ \\
\hline Aspidosperma multiflorum A. DC. & savânica & & & & $3.16(31)$ & $8.89(7)$ & \\
\hline Hymenaea stigonocarpa Hayne & savânica & $5.39(16)$ & & & $0.31(118)$ & $8.82(8)$ & \\
\hline Campomanesia aromatica (Aubl.) Griseb. & savânica & & & & & $8.6(9)$ & \\
\hline Parkia platycephala Benth. & savânica & & & & & $8.48(10)$ & \\
\hline Guettarda viburnoides Cham. \& Schltdl. & savânica & & & & & $6.97(11)$ & \\
\hline Plathymenia reticulata Benth. & savânica & & $2.24(38)$ & $4.12(18)$ & $0.42(101)$ & $5.83(13)$ & \\
\hline Tapirira guianensis Aubl. & florestal & & $1.09(65)$ & & $3.76(25)$ & & $19.94(3)$ \\
\hline Caryocar brasiliense Cambess. & savânica & $2.83(31)$ & $2.72(31)$ & $1.88(33)$ & $2.72(36)$ & & $16.48(4)$ \\
\hline Magonia pubescens A. St.-Hil. & generalista & & $1.59(53)$ & & $2.69(37)$ & $5.54(16)$ & $13.51(6)$ \\
\hline Terminalia argentea Mart. & savânica & $0.38(87)$ & $3.26(27)$ & $5.66(15)$ & $0.59(92)$ & & $11.11(8)$ \\
\hline
\end{tabular}

camente distintos: (1) os cerradões meridionais que são mais florestais e com poucas conexões florísticas com o cerrado lato sensu e (2) os cerradões setentrionais (do nordeste) que seria mais savânicos e florísticamente mais similar ao cerrado lato sensu que também foi chamado de "cerradão de cerrado". Outros estudos também destacaram a região NE como um dos seis grupos florístico do bioma (Ratter et al. 2003; Bridgewater et al. 2004).

As áreas DF e MT também apresentaram elevado número de espécies exclusivas (33 e 55 espécies respectivamente). A localização da área DF, no centro da área core do bioma, pode ter contribuido para a quantidade de espécies exclusivas amostradas (Felfili et al. 2008). O elevado número de elementos florísticos exclusivos da área MT pode ser atribuído à localização de sua área de amostragem no médio rio Araguaia, próximo ao bioma Amazônico, e incorporando espécies deste bioma (como Protium unifoliolatum Engl. e Ephedranthus parviflorus S. Moore).

A comparação com outros estudos realizados em áreas de cerradão, encontrados na literatura, torna-se difícil na medida em que nenhum outro estudo realizou o esforço amostral de 1 ha com parcelas de 20 x 50 m e critério de inclusão $\mathrm{D}_{30} \geq 5 \mathrm{~cm}$. Mesmo assim, a despeito das diferenças metodológicas, destacamos aqueles que obtiveram riqueza elevada: Uberlândia, MG (93); Canarana, MT (95) e Silvânia, GO (89). Destes apenas Canarana e Uberlândia tiveram esforço amostral de 1 ha. Por outro lado, a área MS se destacou das demais por apresentar baixa riqueza (49 espécies).

A análise quantitativa e qualitativa mostrou elevada dissimilaridade entre as seis áreas analisadas, mas com evidência de compartilhamento de espécies entre TO e MG e entre MG e DF. Felfili et al. (2004) chamaram atenção para a elevada similaridade florística entre áreas de cerrado stricto sensu no Planalto central brasileiro, ocorrendo, inclusive, compartilhamento de espécies entre áreas de distintos sistemas de terra. Assim, as áreas TO, MG e DF, apresentaram grau de similaridade florística provavelmente associado à sua relativa proximidade geográfica, quando comparadas às outras áreas. Neste caso, a análise de similaridade complementou a comparação feita a partir da quantidade de espécies exclusivas registradas nas seis áreas investigadas. Felfili et al. (2008) já haviam demonstrado a relação entre diferentes unidades fisiográficas e a distribuição de espécies, destacando a Chapada Pratinha, na região central do bioma.

A classificação das espécies de acordo com sua preferência de hábitat corrobora com outros estudos que já indicavam que a flora do cerradão é composta por uma mistura de elementos florísticos do cerrado stricto sensu e

Tabela 7. Preferência por habitat das espécies arbóreas $\left(\mathrm{D}_{30} \geq 5 \mathrm{~cm}\right)$ que representam mais de $50 \%$ do Valor de Importância (VI) nas áreas de cerradão inventariadas (10 parcelas de 20 x 50 m em cada área). ARIE de Cerradão, Brasília (DF); Paracatu (MG); Dois Irmãos do Buriti (MS); Parque Estadual Araguaia (MT); Parque Nacional Sete Cidades (PI); Rio da Conceição (TO). Valores entre parênteses representam a proporção de espécies em relação ao total 50\%VI (\%).

\begin{tabular}{|c|c|c|c|c|c|c|}
\hline & DF & MG & MS & MT & PI & TO \\
\hline $50 \% \mathrm{VI}$ & 14 & 14 & 7 & 20 & 14 & 10 \\
\hline Florestal & $5(36)$ & $6(43)$ & $3(43)$ & $14(70)$ & $1(7)$ & $4(40)$ \\
\hline Savânica & $8(57)$ & $6(43)$ & $4(57)$ & $4(20)$ & $11(79)$ & $5(50)$ \\
\hline Generalista & $1(7)$ & $2(14)$ & 0 & $2(10)$ & $2(14)$ & $1(10)$ \\
\hline
\end{tabular}


das matas associadas ao bioma (Felfili et al. 1994; Costa \& Araújo 2001; Walter 2006; Mendonça et al. 2008; Ribeiro \& Walter 2008), além de um grupo pequeno de espécies generalistas, que apresentam elevadas densidades e dominância nas comunidades de cerradão. Walter (2006) ainda destaca que o cerradão compartilha 340 espécies com o cerrado stricto sensu, $303 \mathrm{com}$ as matas de galeria e 178 com as matas secas.

Com exceção da área MT, que apresentou maior participação das espécies florestais, as demais áreas apresentaram maior número de espécies savânicas que florestais. Portanto, o padrão geral dessas cinco áreas foi maior expressão de espécies savânicas, confirmando a hipótese de maior similaridade florística do cerradão com o cerrado stricto sensu (Costa \& Araújo 2001; Ribeiro \& Walter 2008). Devemos notar que nas áreas MS, PI e TO as maiores proporções de espécies savânicas podem ter correlação com a estrutura mais aberta registrada nestas áreas (menor densidade e área basal). A exceção da área MT pode ser uma consequência de sua proximidade ao ecótono com a floresta amazônica, apresentando compartilhamento maior com espécies amazônicas, o que lhe afere estrutura mais florestal, como reflexo dos elevados valores de densidade e área basal registrado pelo referido grupo de espécies.

As espécies que foram amostradas nas seis áreas apresentam ampla distribuição pelo bioma Cerrado, destacado por Ratter et al. (2003) dentre as espécies lenhosas que ocorreram em mais de 50\% (158 áreas) das 376 áreas de cerrado lato sensu estudadas por esses autores. As espécies savânicas Qualea grandiflora, Qualea parviflora e Bowdichia virgilioides apresentaram a mais ampla distribuição no Cerrado, ocorrendo em mais de $75 \%$ das áreas estudadas por Ratter et al. 2003. Fica claro a ampla disseminação destas três espécies tanto em áreas de cerrado stricto sensu como em áreas de cerradão, tendo importância destacada tanto em formações savânicas como florestal.

Assim, podemos considerar que o cerradão é uma formação florestal com estreitas conexões florísticas com o cerrado stricto sensu, com ocorrência de espécies savânicas típicas que apresentam ampla distribuição por todo o Cerrado (Bridgewater et al. 2004). As onze espécies que ocorreram em cinco das seis áreas pertencem ao grupo seleto de 121 espécies classificadas como oligárquicas de ampla distribuição e que dominam a flora lenhosa do Cerrado (Bridgewater et al. 2004). A maior parte destas espécies apresentou elevados valores de importância em diversos estudos realizados em áreas de cerradão (Felfili et al. 2007; Felfili et al. 1994; Marimon-Júnior \& Haridasan 2005; Marimon et al. 2006; Pereira-Silva et al. 2004; Kunz et al. 2009). Durigan et al. (2003) apontou que Copaifera langsdorffii foi uma das espécies que ocorreram em mais de $60 \%$ das 86 áreas estudadas de cerrado lato sensu no estado de São Paulo, junto com Qualea grandiflora, Roupala montana, Platypodium elegans, Xylopia aromatica, Caryocar brasiliense, Machaerium acutifolium, Tapirira guianensis e
Protium heptaphyllum. Qualea multiflora, Terminalia argentea, Roupala montana, Copaifera langsdorffi e Caryocar brasiliense não foram amostradas no cerradão do PI corroborando o que Castro et al. (1998) já haviam constatado para dez áreas de cerrado stricto sensu amostradas no Nordeste brasileiro, indicando que estas espécies não fazem parte da flora do cerrado marginal do NE. Em contrapartida C. brasiliense e C. langsdorffii são localmente substituídos por espécies congenéricas nordestinas, respectivamente $C$. coriaceum e C. coriacea.

$\mathrm{Na}$ análise da quantidade de espécies que dominam o valor de importância da comunidade, o padrão apresentado de oligarquia - ou seja, domínio da comunidade por poucas espécies (Ratter et al. 2003) - é bastante comum para áreas de cerrado lato sensu (Bridgewater et al. 2004; Felfili et al. 2008). Ecologicamente isso pode indicar que um grupo restrito de espécies apresenta vantagens competitivas obtendo maior domínio na comunidade. Franco (2002) apontou que diferenças ecofisiológicas das espécies, como profundidade de raizes (superficiais ou profiundas), fenologia (sempreverdes ou decíduas) e período de brotamento de folhas novas (estação seca ou chuvosa) podem servir como mecanismos de adaptação às condições de estresse hídrico, permitinado um compartilhamente dos recursos, podendo contribuir para a manutenção da elevada riqueza de espécies (Franco 2002). Haridasan (2005) destacou que algumas espécies com elevada abundância em comunidades de cerrado stricto sensu apresentam vantagem competitiva ao serem menos exigentes em nutrientes por apresentarem menores concentrações de nutrientes nas folhas (como Qualea parviflora, Qualea grandiflora, Tachigali vulgaris e Caryocar brasiliense). Segundo este autor, outros aspectos que podem contribuir para a menor exigência em nutrientes no solo por parte destas espécies são a capacidade de fixação de nitrogênio por espécies da família Leguminosae e a acumulação de alumínio por espécies das famílias Vochysiaceae, Rubiaceae e Melastomataceae, o que constitui um mecanismo para superar a elevada concentração deste elemento nos solos do Cerrado.

Algumas espécies típicas de formações florestais apresentaram destaque em algumas áreas de cerradão. Nas áreas MT e TO, Protium heptaphyllum e Tapirira guianensis, por exemplo, apesentaram destaque com elevado VI. Estas duas espécies apresentam ampla distribuição no bioma Cerrado, principalmente nas matas de galeria, mas ocorrendo desde a Floresta Amazônica até a Mata Atlântica (Oliveira-Filho et al. 1990; Oliveira-Filho \& Ratter 1995, Ratter et al. 2006; Matos \& Felfili 2010). Estas espécies também se destacam com elevado VI em outras comunidades de cerradão nos estados de: Mato Grosso (Oliveira-Filho et al. 1990; Ratter 1987; Kunz et al. 2009), São Paulo (Gomes et al. 2004), Mato Grosso do Sul (Dubs 1992; Camilotti 2006) e no Distrito Federal (Felfili et al. 1994). Outras espécies como Protium unifoliolatum Engl. e Ephedranthus parviflorus S. Moore, presentes na área MT, apresentam distribuição restrita à 
região amazônica (JBRJ 2010). Estes elementos florísticos em conjunto com espécies que são comuns aos biomas Cerrado e Amazônia (Himatanthus sucuuba, Lacistema aggregatum (P.J.Bergius) Rusby, Andira cuiabensis Benth., Aenigmanthera lasiandra (A.Juss.) W.R.Anderson e Mollia lepidota Spruce ex Benth.) demonstram a clara influência florística da região amazônica no cerradão do Parque Estadual do Araguaia, MT.

O cerradão do Piauí apresentou espécies de distribuição restrita a esta região ecotonal (Castro et al. 1998): Copaifera coriacea, Dimorphandra gardineriana Tul., Mimosa verrucosa Benth. e Stryphnodendron coriaceum (Mart.) Coville. Além destas destacam-se algumas espécies que ocorrem em maior abundância na Amazônia e Caatinga: Campomanesia aromatica, Parkia plathycephala, Combretum leprosum Mart. e Combretum mellifluum Eichler (Castro et al. 1998; Mendonça et al. 2008). Estes elementos florísticos, extrínsecos ao Cerrado, junto com a quantidade de espécies exclusivas do cerradão do PI apóiam a idéia de marginalidade desta parte do bioma.

Em relação à participação das diferentes categorias de espécies de acordo com sua preferência por habitat (para as espécies que somaram $50 \%$ do IVI) notam-se três padrões. O primeiro padrão evidencia a noção de flora mista do cerradão, a comunidade sendo dominado por pequeno grupo de espécies de formação florestal e cerrado stricto sensu. Os cerradões da área core de MG e TO, seguem esse padrão já descrito em outros estudos, com destacada importância para Copaifera langsdorffii, Emmotum nitens e Qualea grandiflora (Felfili et al., 1994). O segundo padrão, de domínio de espécies de formação florestal, denota o extremo da condição florestal do cerradão. Este padrão reflete a influência florestal da região Amazônica na estrutura e composição do cerradão da área MT e mostra a grande variação que o cerradão pode ter, ainda mais quando próximo da região Amazônica. As espécies Protium heptaphyllum e Hirtella glandulosa dominaram o cerradão do MT sendo bastante comum em outros cerradões do leste do Mato Grosso (Ratter et al. 1978, Marimon et al. 2006). O terceiro padrão, de domínio de espécies savânicas, mostra o padrão descrito para o cerradão (Ribeiro \& Walter 2008) já que é esperada maior semelhança florística com o cerrado stricto sensu. No cerradão do PI este padrão se reflete na estrutura da vegetação que apresentou menor cobertura do que os demais cerradões, corroborando com a hipótese de que os cerradões da região marginal do Piauí são mais savânicos do que cerradões do centro e sul do bioma Cerrado (Castro \& Martins 1999), dominadas por típicas espécies savânicas do nordeste: Copaifera coriacea, Campomanesia aromatica e Parkia plathycephala. Na área do DF apesar de haver maior proporção de espécies savânicas como Qualea grandiflora e Miconia burchelli, houve participação significativa de espécies florestais nos 50\% do VI, como Emmotum nitens e Ocotea pomaderroides.

\section{Conclusão}

O padrão co-ocorrente para o cerradão é a presença de espécies das categorias florestais, savânicas e generalistas, de acordo com sua preferência por habitat. Apesar de haver mistura de elementos florísticos do cerrado stricto sensu e formações florestais, foi detectado maior número de espécies savânicas nas áreas de cerradão, o que corrobora com a nossa hipótese de trabalho, com exceção da área MT, que apresentou maior proporção de espécies florestais evidenciando a influência da proximidade com o bioma Amazônico, o que pode ter influenciado no porte mais florestal registrado neste cerradão. A área PI se destacou das demais por apresentar proporção maior de espécies savânicas, especialmente entre as espécies que dominaram a comunidade.

As seis áreas de cerradão analisadas não apresentaram estrutura homogênea ou consistência florística, apresentando-se como fisionomia bastante heterogênea. Assim, estruturalmente, a vegetação lenhosa apresentou grandes variações com formações mais abertas e mais densas. A elevada quantidade de espécies exclusivas junto com o padrão geral de dissimilaridade nas seis áreas indica grande heterogeneidade da distribuição da flora lenhosa do cerradão, seguindo o que já foi jencontrado para outras fisionomias do bioma Cerrado. O conjunto de dados analisados confirma a nossa hipótese inicial, destacando-se algumas espécies que, ocorrendo em conjunto, podem ser usadas para tipificar o cerradão: Emmotum nitens, Qualea grandiflora, Tachigali vulgaris, Copaifera langsdorffii, Vatairea macrocarpa e Bowdichia virgilioides.

\section{Agradecimentos}

Ao CNPq pela bolsa de doutorado concedida ao primeiro autor e pela bolsa de produtividade em pesquisa à Dra. Jeanine Maria Felfili. Ao Programa de Pós-graduação em Ecologia da Universidade de Brasília pelo apoio financeiro através de recurso da CAPES. Ao BIOTEN (PELD - Sítio 10), pelo financiamento do inventário realizado no PI. Á contribuição da professora Beatriz S. Marimon (Departamento de Biologia - UNEMAT), professor Alberto Jorge Farias de Castro (Departamento de Biologia - UFPI), Ruth Raquel Farias (Departamento de Biologia - UFPI) e Ricardo Flores Haidar (OIKOS Pesquisa Aplicada) no planejamento e execução das expedições de campo. Também somos gratos a valiosa ajuda nos trabalhos de campo dada por Herson S. Lima, ex Diretor do Parque Estadual do Araguaia, e pelo Newton Rodrigues, técnico da Universidade de Brasília, além do auxílio dos alunos de graduação e colegas de pós-graduação.

\section{Referências Bibliográfica}

Angiosperm Phylogeny Group (APG II). 2003. An update of the Angiosperm Phylogeny Group classification for the orders and families of flowering plants: APG II. Botanical Journal of the Linnaean Society 141(41): 399-436. 
Araújo, G.M. 1984. Comparação do estado nutricional de dois cerradões em solos distrófico e mesotrófico no planalto central do Brasil. Dissertação de Mestrado. Universidade de Brasília, Brasília.

Askew, G.; Moffatt, D.J.; Montgomery, R.F. \&. Searl, P.L. 1970. Soil Landscapes in Mato Grosso. Geographical Journal 136: 211-227.

Askew, G.P.; Montgomery, R.F. \& Searl, P.L. 1971. Soil and soil moisture as factors influencing the distribution of the vegetation formations of the Serra do Roncador, Mato Grosso. Pp. 150-160. In: Ferri, M.G. (Ed.). III Simpósio sobre o Cerrado. São Paulo, Edgard Blücher.

Aubréville, A. 1959. As florestas do Brasil: estudo fitogeográfico e florestal. Anuário Brasileiro de Economia Florestal 11(11): 201-232.

Bridgewater, S.; Ratter, J.A. \& Ribeiro, J.F. 2004. Biogeographic patterns, beta-diversity and dominance in the Cerrado biome of Brazil. Biodiversity and Conservation 13: 2295-2318.

Camilotti, D.C. 2006. Análise da vegetação arbórea em um remanescente de cerradão em Bandeirantes, MS. Dissertação de Mestrado em Ecologia, Universidade Federal de Mato Grosso do Sul/UFMS, Campo Grande.

Castro, A.A.J.F. \& Martins, F.R. 1999. Cerrados do Brasil e do Nordeste: caracterização, área de ocupação e considerações sobre a sua fitodiversidade. Pesquisa Foco 7(9): 147-178.

Castro, A.A.J.F.; Martins, F.R. \& Fernandes, A.G. 1998. The woody flora of Cerrado vegetation in the State of Piauí, Northeastern Brazil. Edinburgh Journal of Botany 55(3): 455-472.

Cochrane, T.T.; Sanchez, L.G.; Azevedo, L.G.; Porras, J.A. \& Garver, C.L. 1985. Land in Tropical America. 3 vols. Cali, CIAT/EMBRAPA.

Costa, A. \& Araújo, G. 2000. Comparação da vegetação arbórea de cerradão e de cerrado na Reserva do Panga, Uberlândia, Minas Gerais. Acta Botancica Brasilica 15(1): 63-72.

Coutinho, L.M. 1978. O conceito de cerrado. Revista Brasileira de Botânica 1: 17-23.

Curtis J.T. \& McIntosh R.P. 1950. The interrelations of certain analytic and synthetic phytosociological characters. Ecology 31: 434-455.

Curtis J.T. \& McIntosh R.P. 1951. An upland forest continuum in the prairie-forest border region of Wisconsin. Ecology 32: 476-496.

Dubs, B. 1992. Observations on the differentiation of woodland and wet savanna habitats in the Pantanal of Mato Grosso, Brazil. Pp. 431-450. In: Furley, P.; Proctor, J. \& Ratter, J.A. (Orgs.) Nature and Dynamics of forest-savanna boundaries. New York, Chapman \& Hall.

Durigan, G.; Siqueira, M.F.; Franco, G.A.D.C.; Bridgewater, S. \& Ratter, J. A. (2003). The vegetation of priority areas for Cerrado conservation in São Paulo State, Brazil. Edinburgh Journal of Botany 60: 217-241.

Eiten, G. 1978. Delimitation of the Cerrado concept. Vegetatio 36(3): 169-178.

Felfili J.M.; Filgueiras T.S.; Haridasan M.; Silva Júnior M.C.; Mendonça R. \& Rezende, A.V. 1994. Projeto biogeografia do bioma cerrado: Vegetação e solos. Cadernos de geociências do IBGE 12: 75-166.

Felfili, J.M \& Silva-Júnior, M.C. 2001. Biogeografia do Bioma Cerrado: estudo fitofisionômico na Chapada do Espigão Mestre e do São Francisco. Universidade de Brasília, Faculdade de Tecnologia, Departamento de Engenharia Florestal, Brasília.

Felfili, J.M.; Carvalho, F.A. \& Haidar, R.F. 2005. Manual para o monitoramento de parcelas permanentes nos biomas Cerrado e Pantanal. Brasília, Universidade de Brasília, Departamento de Engenharia Florestal.

Felfili, J.M.; Mendonça, RC.; Munhoz, C.B.R.; Fagg, C.W.; Pinto, J.R.R.; Silva-Júnior, M.C. \& Sampaio, J.C. 2004. Pp. 1-126. Vegetação e flora da APA Gama e Cabeça de Veado. In: J.M. Felfili; A.A.B. Santos; J.C. Sampaio. Universidade de Brasília, Departamento de Engenharia Florestal, Brasília.

Felfili, J.M.; Rezende, A.C.; Silva-Júnior, M.C.; Nogueira, P.E.; Walter, B.M.T; Encinas, J.I. \& Silva, M.A. 2007. Fitossociologia da vegetação arbórea. Pp. 45-98. In: Felfili, J.M.; Rezende, A.V. \& Silva-Júnior, M.C. (Orgs.). Biogeografia do Bioma Cerrado: vegetação e solos da Chapada dos Veadeiros. Brasília, FINATEC.

Felfili, M.J; Felifili, M.C.; Nogueira, P.E.; Silva, J.F; Fariñas, M.R.; Nunes, M.; Silva-Júnior, M.C.; Rezende, A.V. \& Fagg, C.W. 2008. Padrões fitogeográficos e sua relação com sistemas de terra no bioma Cerrado.
Pp. 215-228. In: Sano, S.M.; Almeida, S.P. \& Ribeiro, J.F. (Eds.). Cerrado: ecologia e flora v.1. Embrapa Informação Tecnológica, Brasília.

Furley, P.A. \& Ratter, J.A. 1988. Soil resources and plant communities of the central Brazilian Cerrado and their development. Journal of Biogeography 15(Special): 97-108

Gomes, B.Z.; Martins, F.R. \& Tamashiro, J.Y. 2004. Estrutura do cerradão e da transição entre cerradão e floresta paludícola num fragmento da International Paper do Brasil Ltda., em Brotas, SP. Revista Brasileira de Botânica 27(2): 249-262.

Goodland, R.J. \& Ferri, M.G. 1979. Ecologia do cerrado. São Paulo, EdUSP. Guarim, V.L.M.S.; Moraes, E.C.C.; Prance, G.T \& Ratter, J.A. 2000. Inventory of a mesotrophic Callisthene cerradão in the Pantanal of Mato Grosso, Brazil. Edinburgh Journal of Botany 57(3): 429-436.

Guilherme, F.A.G. \& Nakajima, J.N. 2007. Estrutura da vegetação arbórea de um remanescente ecotonal urbano floresta-savana no Parque do Sabiá, em Uberlândia, MG. Revista Árvore 31(2): 329-338.

Haridasan, M. 2005. Competição por nutrientes em espécies arbóreas do Cerrado. Pp. 168-178. In: Scariot, A.; Sousa-Silva, J.C. \& Felfili, J.M. (Orgs.). Cerrado: ecologia, biodiversidade e conservação. Brasília, Ministério do Meio Ambiente.

Heringer, E.P.; Barroso, G.M.; Rizzo, J.A. \& Rizzini, C.T. 1977. A flora do Cerrado. Pp. 211-232. In:. Ferri, M.G (Ed.). IV Simpósio sobre o Cerrado: bases para a utilização agropecuária. São Paulo, EDUSP.

Hijmans, R.J.; Cameron, S.E.; Parra, J.L.; Jones, P.G. \& Jarvis, A. 2005. Very high resolution interpolated climate surfaces for global land areas. International Journal of Climatology 25: 1965-1978.

IBAMA - Instituto Brasileiro do Meio Ambiente e dos Recursos Naturais Renováveis. 2010. Monitoramento do Cerrado. http://siscom.ibama. gov.br/monitorabiomas/cerrado/index.htm (Acesso em 25/09/2010).

INMET - Instituto Nacional de Meteorologia. 2010. Normas Climatológicas. http:// www.inmet.gov.br/sonabra/maps/automaticas. php (Acesso em 31/09/2010).

Kent, M. \& Coker, P. 1992. Vegetation Description and Analysis. London. Belhaven Press.

Klink, C.A.; Machado, R. 2005. Conservation of the Brazilian Cerrado. Conservation Biology 19(3): 707-713.

Kunz, S.H.; Ivanauskas, N.M. \& Martins, S.V. 2009. Estrutura fitossociológica de uma área de cerradão em Canarana, Estado do Mato Grosso, Brasil. Acta Scientiarum. Biological Sciences 32(3): 255-261.

Magalhães, G.M. 1966. Sobre os cerrados de Minas Gerais. Anais da Academia Brasileira de Ciências 38: 59-69.

Magurran, A.E., 1988. Ecological diversity and its measurement. London, Croom Helm Limited.

Marimon, B.S.; Lima, E.S.; Duarte, T.G.; Chieregatto, L.C. \& Ratter, J.A. 2006. Observations on the vegetation of northeastern Mato Grosso, Brazil. IV: an analysis of the Cerrado-Amazonian forest ecotone. Edinburgh Journal of Botany 63(2-3): 3323-341.

Marimon-Junior, B.H. \& Haridasan, M. 2005. Comparação da vegetação arbórea e características edáficas de um cerradão e um cerrado sensu stricto em áreas adjacentes sobre solo distrófico no leste de Mato Grosso, Brasil. Acta Botanica Brasilica 19(4): 913-926.

Matos, M.Q. \& Felfili, J.M. 2010. Florística, fitossociologia e diversidade da vegetação arbórea nas matas de galeria do Parque Nacional de Sete Cidades (PNSC), Piauí, Brasil. Acta Botanica Brasilica 24(2): 483-496.

McCune B. \& Mefford, M.J. 1997. PC-ORD: Multivariate analysis of ecological data. Version 4.0. MjM Software, Glenden Beach, Oregon.

Mendonça, R.C.; Felfili, J.M.; Walter, B.M.T.; Silva-Júnior; Rezende, A.B.; Filguerias, T.S.; Nogueira, P.E. \& Fagg, C.W. 2008. Flora Vascular do Bioma Cerrado: checklist com 12.356 espécies. Pp. 213-228. In: Sano, S.M.; Almeida, S.P. \& Ribeiro, J.F. (Eds.). Cerrado: Ecologia e Flora. Volume 1. Brasília, Embrapa Cerrados.

Miranda, I.S.; Almeida, S.S. \& Dantas, P.J. 2006. Florística e estrutura de comunidades arbóreas em cerrados de Rondônia, Brasil. Acta Amazônica 36(4): 419-430.

Mittermeier, R.A.; GIL, P.R.; Hoffmann, M.; Pilgrim, J.D.; Brooks, T.; Mittermeier, C.G; Fonseca, G.A.B. 2004. Hotspots Revisited: Earth s Biologically Richest and Most Endangered Ecoregions. v. 1. México, CEMEX \& Agrupacion Sierra Madre. 
Mueller-Dombois, D. \& Ellenberg, H. 1974. Aims and methods of vegetation ecology. New York, John Willey \& Sons.

Myers, N.; Mittermeier, R.A.; Mittermeier C.G.; Fonseca, G.A.B. \& Kent, J. 2000. Biodiversity hotspots for conservation priorities. Nature 403: 853-858.

Oliveira-Filho, A.T. \& Ratter, J.A. 1995. A study of the origin of central Brazilian forests by the analysis of plant species distribution patterns. Edinburgh Journal of Botany 52(2): 141-194.

Oliveira-Filho, A.T. \& Ratter, J.A. 2002. Vegetation physiognomies and woody flora of the Cerrado Biome. Pp. 91-120. In: Oliveira, P.S. \& Marquis, R.J. (Orgs.). The Cerrados of Brazil: ecology and natural history of a Neotropical savanna. New York, Columbia University Press.

Oliveira-Filho, A.T.; Ratter, J.A. \& Shepherd, G.J. 1990. Floristic composition and community structure of a Brazilian gallery forest. Flora 184: 103-117.

Pereira-Silva, E.F.L.; Santos, J.E.; Kageyama, P.Y. \& Hardt, E. 2004. Florística e fitossociologia dos estratos arbustivo e arbóreo de um remanescente de cerradão em uma Unidade de Conservação do Estado de São Paulo. Revista Brasileira de Botânica 27(3): 533-544.

Pielou, E.C. 1974. Population and Community Ecology. New York, Gordon and Breach.

Ratter, J.A. 1987. Notes on the vegetation of the Parque Nacional do Araguaia (Brazil). Notes of the Royal Botanic Gardens, Edinburgh 44: 311-342.

Ratter, J.A.; Askew, G.P.; Montgomery, R.F. \& Gifford, D.R. 1977. Observações adicionais sobre o cerradão de solos mesotróficos no Brasil central. Pp. 303-316. In: Ferri, M.G. (Ed.). IV Simpósio sobre o Cerrado: bases para a utilização agropecuária. São Paulo, EDUSP.

Ratter, J.A.; Askew, G.P.; Montgomery, R.F. \& Gifford, D.R. 1978. Observations on forests of some mesotrophic soils in central Brazil. Revista Brasileira de Botânica 1: 47-58.

Ratter, J.A.; Bridgewater, S. \& Ribeiro, J.F. 2003. Analysis of the floristic composition of the Brazilian Cerrado vegetation. III. Comparison of the woody vegetation of 376 areas. Edinburgh Journal of Botany 60: $57-109$.

Ratter, J.A.; Bridgewater, S. \& Ribeiro, J.F. 2006. Biodiversity patterns of the woody vegetation of the brazilian Cerrado. Pp. 31-66 In: Penington, T. \& Ratter, J.A. (Orgs.). Neotropical Savannas and Seasonally Dry Forests. Boca Raton, CRC Press.
Ratter, J.A.; Richards, P.W.; Argent, G. \& Gifford D.R. 1973. Observations on the vegetation of north eastern Mato Grosso I: The woody vegetation types of the Xavantina-Cachimbo Expedition Area. Philosophical Transactions of the Royal Society of London B 226: 449-492.

Ribeiro J.F.; Silva, J.C.S. \& Batmanian, G.J. 1985. Fitossociologia de tipos Fisionômicos de cerrado em Planaltina - DF. Revista Brasileira de Botânica 8: 131-142.

Ribeiro, J.F. \& Walter, B.M.T. 2008. As principais fitofisionomias do Bioma Cerrado. Pp. 151-212. In: Sano, S.M.; Almeida, S.P. \& Ribeiro, J.F. (Eds.). Cerrado: Ecologia e Flora. Brasília, Embrapa Cerrados.

Rizzini, 1963. A flora do cerrado, análise florística das savanas centrais. Pp. 125-177. In: Anais do I Simopósio sobre o cerrado. São Paulo, 1962.

Sano, E.E.; Rosa, R.; Brito, J.L.S. \& Ferreira, L.G. 2010. Land cover mapping of the tropical savanna region in Brazil. Enrironmental Monitoring and Assessment 166: 113-124.

Silva, H.G.; Figueiredo, N. \& Andrade, G.V. 2008. Estutura da vegetação de um cerradão e a heterogeneidade regional do Cerrado no Maranhão, Brasil. Revista Árvore 32(5): 921-930.

Silva, J.F.; Farinãs, M.R.; Felfili, J.M. \& Klink, C.A. 2006. Spatial heterogeneity, land use and conservation in the cerrado region of Brazil. Journal of Biogeography 33: 536-548.

Solórzano, A. 2011. Análise Fitogeográfica do cerradão: conexões florísticas, padrões estruturais, relações ecológicas e modelagem de sua distribuição potencial. Tese de Doutorado, Programa de Pósgraduação em Ecologia, Universidade de Brasília, Brasília

Veloso, H.P. 1948. Fitofisionomia e algumas considerações sobre a vegetação do Centro-Oeste brasileiro. Memórias do Instituto Oswaldo Cruz 46(4): 813-852.

Waibel, L.H. 1948. Vegetação e uso da terra no Planalto Central do Brasil. Revista Brasileira de Geografia 10(3): 335-370.

Walter, B.M.T. 2006. Fitofisionomias do bioma Cerrado: síntese terminológica e relações florísticas. Pp. 373 Tese de Doutorado, Programa de Pós-graduação em Ecologia, Universidade de Brasília.

Warming, E. 1908. Lagoa Santa: Contribuição para a geographia phytobiologica. Belo Horizonte, Imprensa Oficial de Minas Gerias.

Zar, J.H. 1996. Biostatistical analysis. 3 ed. New Jersey, Prentice-Hall. 